\title{
Mathematical analysis of biogas generation in a waste water digester
}

\author{
M. Rajaram ${ }^{1 *}$, A. Meena ${ }^{2}$ and N. Deena ${ }^{3}$
}

\begin{abstract}
A mathematical model of anaerobic digestion of waste water is discussed in this paper. This model contains system of non-linear ordinary differential equations. Homotopy perturbation method is implemented to find the analytical solution of system of non-steady-state ordinary differential equations. Analytical expression of concentration of carbon in different forms (organic matter, volatile fatty acids, acetic acid, inorganic carbon, methane and carbon dioxide) are presented. The obtained results are valid for the whole solution domain. The influence of the kinetic parameters $k_{0}, \ldots, k_{6}$ were discussed in Figures. The analytical results were compared with numerical results and are found to be in good agreement.
\end{abstract}

\section{Keywords}

Mathematical modelling, non-linear ordinary differential equations, Homotopy perturbation method, Numerical simulation.

AMS Subject Classification 00A05, 03E70, 03B52.

1,2,3 Department of Mathematics, Saraswathi Narayanan College, Perungudi, Madurai-625022, Tamil Nadu, India.

*Corresponding author: ${ }^{*}$ rajaram23292@gmail.com; ${ }^{2}$ meensphd@gmail.com

Article History:Received 11 December 2018; Accepted 12 February 2019

(C)2019 MJM.

\section{Contents}

\section{1}

2 Mathematical formulation of the problem. 102

3 Analytical expressions of concentrations ........ 103

4 Numerical simulation ........................ 105

5 Sensitivity analysis ......................... 105

6 Results and discussion ................... 105

7 Conclusion ................................... 105

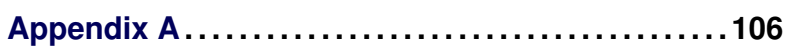

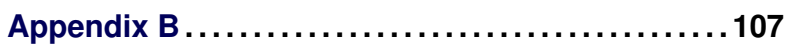

Appendix C..............................

References $\ldots \ldots \ldots \ldots \ldots \ldots \ldots \ldots \ldots \ldots \ldots \ldots, 112$

\section{Introduction}

Municipal solid waste generation is increasing in indian urban areas and started creating enormous waste disposal problems in the recent past [1]. For example, municipal solid wastes, water hyacinth, sugar mill press mud waste, and fruit and vegetable processing wastes have been reported [2]. The process of digestion and production of biogas depends on the composition of feedstock and the fermentation products of the vegetable wastes. Most of the vegetable are cultivated seasonally. Accordingly the type of wastes generated varies considerably in quantity and composition. Therefore it is necessary to study the effects of variation in the composition of vegetable wastes on the performance of anaerobic digestion process [2].

Kinetic studies of anaerobic digestion process are useful to predict the performance of digesters and design appropriate digesters. Kinetic studies are also helpful in understanding inhibitory mechanisms of biodegradation [1]. The theoretical studies of anaerobic digestion process helps to optimize the methane gas evolution from the vegetable waste, to analyze the operational parameters, such as characteristics of substrates, organic loading and hydraulic retention time, for the stability of anaerobic digestion system and to get an understanding of the anaerobic digestion of the vegetable wastes under ambient temperature conditions by conducting a lab scale study and hence to investigate the biogas yield and the kinetics of anaerobic digestion of vegetable waste fed [3-5].

The process of developing a mathematical model is termed mathematical modelling. Mathematical models are used in the natural sciences (such as physics, biology, earth, sciences, chemistry) and engineering disciplines (such as computer 
science, electrical engineering) as well as in the social sciences (such as economics, psychology, sociology, political sciences) using homotopy perturbation method HPM [6, 7].

The homotopy perturbation method (HPM) is a powerful and efficient technique for finding solutions of nonlinear differential equations. The method was first introduced by $\mathrm{He}$ [8-11] in 1998 HPM is a combination of the perturbation and homotopy. This method can take the advantages of the conventional perturbation method while elimating its restrictions. In general, this method has been successfully applied to solve many kinds of linear and nonlinear equations in science and engineering.

V. Dhanalakshmi Sridevi and R.A Ramanujam [2] obtained analytical relation between the volume of biogas produced and digestion time. Recently Santos et.al [12] proposed the kinetic model which predicts the evolution of the different forms of carbon involved in the anaerobic digestion of waste water. The aim of this study is to obtain the analytical expression of concentration of organic matter, volatile fatty acids, acetic acid, inorganic carbon, methane and carbon dioxide for all values of digestion time.

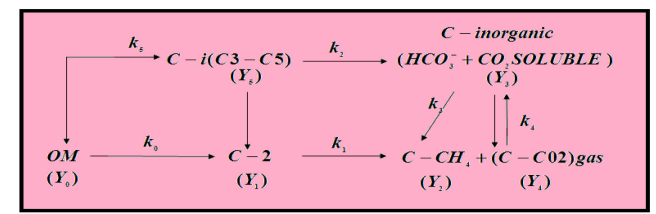

Fig.1:Simplified scheme of the anaerobic digestion [12]

\section{Mathematical formulation of the problem}

The kinetic model can be established using the differential equations as follows [12]:

$$
\begin{gathered}
\frac{d[O M]}{d t}=-k_{0}\left\{[O M]-[O M]_{n b}\right\}- \\
k_{5}\left\{[O M]-[O M]_{n b}\right\} \\
\frac{d\left[C_{i}\right]}{d t}=k_{5}\left\{[O M]-[O M]_{n b}\right\}-k_{0}\left[C_{i}\right]-k_{2}\left[C_{i}\right]^{2} \\
\frac{d\left[C_{2}\right]}{d t}=k_{0}\left\{[O M]-[O M]_{n b}\right\}+k_{6}\left[C_{i}\right]-2 k_{1}\left[C_{2}\right] \\
\frac{d\left[C_{\text {inorganic }}\right]}{d t}=k_{4}\left(480-\left[C_{\text {in }}\right)+\right. \\
k_{3}\left[C_{\text {in }}\right]+k_{3}\left[C_{i}\right]^{2}-f\left\{k_{5}\left\{[O M]-[O M]_{n b}\right\}+\right. \\
\left.k_{0}\left\{[O M]-[O M]_{n b}\right\}\right\} \\
\frac{d\left[C H_{4}\right]}{d t}=k_{1}\left[C_{2}\right]+k_{3}\left[C_{\text {in }}\right]
\end{gathered}
$$

$$
\frac{d\left[C O_{2}\right]}{d t}=k_{1}\left[C_{2}\right]+k_{4}\left[C_{\text {ino }}\right]-480 K_{4},
$$

where $[O M]$ is the concentration of organic matter, $\left[C_{i}\right]$ is the concentration of carbon as volatile fatty acids having carbon atoms, $\left[C_{2}\right]$ is the concentration of acetic acid carbon. $\left[\mathrm{C}_{\text {inorganic }}\right]$ is the total inorganic carbon concentration, $\left[\mathrm{CH}_{4}\right]$ is the concentration of methane, $\left[\mathrm{CO}_{2}\right]$ is the concentration of carbon dioxide, $\left[O M_{n b}\right]$ is the Organic matter bio-degradable and $k_{i} s(i=1$ to 6$)$ are kinetic constants.

The initial condition of Eqns.(2.1) to (2.6) is at

$$
\begin{gathered}
t=0,[O M]=M_{i n},\left[C_{i}\right]=C_{i n},\left[C_{2}\right]=C_{2 i n}, \\
{\left[C_{\text {inorganic }}\right]=C_{\text {inn }},} \\
{\left[\mathrm{CH}_{4}\right]=\mathrm{CH}_{4 i n},\left[\mathrm{CO}_{2}\right]=\mathrm{CO}_{2 i n}}
\end{gathered}
$$

\section{Analytical expressions of concentrations}

Recently, many authors have applied the HPM to various problems and demonstrated the efficiency of the HPM for handling non linear structures and solving various physics and engineering problems. This method is a combination of Homotopy in topology and classic perturbation techniques. The set of expression presented in Eqns.(2.1) to (2.7) defines the initial value problem. The Homotopy perturbation method [8-11] is used to give the approximate solution of non-linear differential Eqns.(2.1) to (2.6). The analytical expression of the organic matter consumption as a function of the biodegradable organic matter concentration is obtained by solving Eqn.(2.1) using HPM as follows:

$$
\begin{aligned}
& {[O M](t)=a+\left(M_{i n}-a\right) e^{-K_{1} t}} \\
& \text { where } K_{1}=k_{0}+k_{5}, a=[O M]_{n b}
\end{aligned}
$$

By substituting Eqn.(3.1) in Eqn.(2.2), we get the analytical expression of $C_{i}$ as follows:

$$
\begin{aligned}
{\left[C_{i}\right](t)=} & \frac{\left(C_{i n} k_{6}+a k_{5}\right) e^{-k_{6} t}}{k_{6}}+ \\
& \frac{k_{5}\left(M_{i n}-a\right)\left(e^{-K_{1} t}-e^{-k_{6} t}\right)}{k_{6}-K_{1}}+ \\
& \frac{a^{2} k_{2} k_{5}^{2}\left(e^{-k_{6} t}-1\right)}{k_{6}^{3}}-\frac{a k_{5} e^{-k_{6} t}}{k_{6}}+ \\
& \frac{k_{2}\left(C_{i n} k_{6}+k_{5} a\right)\left(e^{-2 k_{6} t}-e^{-k_{6} t}\right)}{k_{6}^{2}}+ \\
& \frac{2 t a k_{2} k_{5}\left(C_{i n} k_{6}+a k_{5}\right) e^{-k_{6} t}}{k_{6}^{2}}
\end{aligned}
$$

By substituting Eqn.(3.2) in Eqn.(2.3), we get the analytical 
expression of $C_{2}$ as follows:

$$
\begin{aligned}
{\left[C_{2}\right](t)=} & \frac{a k_{0}\left(1-e^{2 k_{1} t}\right)}{2}+ \\
& \frac{k_{0}\left(M_{i n}-a\right)\left(e^{-K_{1} t}-e^{-2 k_{1} t}\right)}{2 k_{1}-K_{1}}+ \\
& \frac{a k_{5}\left(e^{-2 k_{1} t}-1\right)}{2 k_{1}}+C_{2 i n} e^{-2 k_{1} t}+ \\
& \frac{\left(C_{i i n} k_{6}+a k_{5}\right)\left(e^{-K_{1} t}-e^{-2 k_{1} t}\right)}{2 k_{1}-k_{6}}+ \\
& \frac{a k_{0}\left(e^{-2 k_{1} t}-1\right)}{2}
\end{aligned}
$$

By substituting Eqn.(3.3) in Eqn.(2.4), we get the analytical expression of $C_{i n}$ as follows:

$$
\begin{aligned}
{\left[C_{\text {inorganic }}\right](t)=} & \frac{a k_{2} k_{5}^{2}\left(1-e^{-K_{2} t}\right)}{k_{6}^{2} K_{2}}+\frac{480 k_{4}\left(1-e^{-K_{2} t}\right)}{K_{2}}- \\
& \frac{2 a k_{5}\left(C_{i n} k_{6}+a k_{5}\right)\left(e^{-k_{6} t}-e^{-K_{2} t}\right)}{k_{6}^{2}\left(K_{2}-k_{6}\right)}+ \\
& \frac{f\left(M_{\text {in }}-a\right)\left(K_{1} e^{-K_{1} t}-K_{1} e^{-K_{2} t}\right)}{K_{2}-K_{1}}+ \\
& \frac{k_{2}\left(C_{\text {in }}+a\left(k_{5} / k_{6}\right)\right)^{2}\left(e^{-2 k_{6} t}-e^{-K_{2} t}\right)}{K_{2}-2 k_{6}}+ \\
& C_{\text {inin }} e^{-K_{2} t}
\end{aligned}
$$

where $K_{2}=k_{4}+k_{3}$

By substituting Eqn.(3.4) in Eqn.(2.5), we get the analytical expression of $\mathrm{CH}_{4}$ as follows:

$$
\begin{aligned}
{\left[\mathrm{CH}_{4}\right](t)=} & \frac{a k_{0} d_{1}}{4 k_{1}}+\frac{a^{2} k_{3} k_{2} k_{5}^{2} d_{2}}{k_{6}^{2} K_{2}^{2}}+ \\
& \frac{k_{0}\left(M_{i n}-a\right)\left(K_{1} e^{-2 k_{1} t}-K_{1}+2 k_{1}-2 k_{1} e^{-2 k_{1} t}\right)}{2 K_{1}\left(2 k_{1}-K_{1}\right)}+ \\
& C H_{4 i n}-\frac{a k_{5} d_{1}}{4 k_{1}}-\frac{C_{2 i n}\left(e^{-2 k_{1} t-1}\right)}{2}+ \\
& \frac{480 k_{3} k_{4} d_{2}}{K_{2}^{2}}-\frac{C_{\text {inin }} k_{3}\left(e^{-K_{2} t}-1\right)}{K_{2}}- \\
& \frac{2 a k_{5} k_{3}\left(C_{i n} k_{6}+2 k_{6}\right)\left(K_{2}-K_{2} e^{-k_{6} t}+K_{2} k_{6} e^{-K_{2} t}-K_{2} k_{6}\right)}{k_{6}^{3} K_{2}\left(K_{2}-k_{6}\right)} \\
& +\frac{\left(C_{i n}+k_{6}-a k_{5}\right)\left(k_{6} e^{-2 k_{1} t}-k_{6}+2 k_{1}-2 k_{1} e^{-k_{6} t}\right)}{2 k_{6}\left(2 k_{1}-k_{6}\right)},
\end{aligned}
$$

where $d_{1}=\left(2 t k_{1}+e^{-2 k_{1} t}-1\right), d_{2}=\left(K_{2} t+e^{-K_{2} t}-1\right)$.

By substituting Eqn.(3.5) in Eqn.(2.6), we get the analyti- cal expression of $\mathrm{CO}_{2}$ as follows:

$$
\begin{aligned}
{\left[\mathrm{CO}_{2}\right](t)=} & \frac{a k_{0} d_{1}}{4 k_{1}}+\frac{a^{2} k_{4} k_{2} k_{5}^{2} d_{2}}{k_{6}^{2} K_{2}^{2}}-\frac{a k_{5} d_{1}}{4 K_{1}}+ \\
& \frac{480 k_{4}^{2} d_{2}}{K_{2}^{2}}+\frac{k_{0}\left(M_{i n}-a\right)\left(K_{1} e^{-2 k_{1} t}-K_{1}+2 k_{1}-2 k_{1} e^{-k_{1} t}\right)}{2 K_{1}\left(2 k_{1}-K_{1}\right)} \\
& +C O_{2 i n}-\frac{a k_{0} d_{1}}{4 k_{1}}-480 k_{4} t-\frac{c_{i n i n} k_{4}\left(e^{-K_{2} t}-1\right)}{K_{2}}+ \\
& \frac{\left(C_{i n} k_{6}-a k_{5}\right)\left(k_{6} e^{-2 k_{1} t}-k_{6}+2 k_{1}-2 k_{1} e^{-k_{6} t}\right)}{2 k_{6}\left(2 k_{1}-k_{6}\right)}- \\
& \frac{f k_{4}\left(M_{i n}-a\right)\left(K_{1} e^{-K_{2} t}-K_{1}-K_{2} e^{-2 k_{1} t}+K_{2}\right)}{K_{2}\left(K_{2}-K_{1}\right)}- \\
& \frac{2 a k_{5} k_{4}\left(C_{i n} k_{6}+a k_{5}\right)\left(K_{2}-K_{2} e^{-k_{6} t}+k_{6} e^{-K_{2} t}-k_{6}\right)}{k_{6}^{2} K_{2}\left(K_{2}-k_{6}\right)} \\
& -\frac{C_{2 i n}\left(e^{-2 k_{1} t}-1\right)}{2}
\end{aligned}
$$

The steady state value of concentration of organic matter, volatile fatty acids, acetic acid, and total inorganic carbon can be obtained from the Eqns.(3.1) to (3.4) as follows:

$$
\begin{aligned}
{[O M]_{s s} } & =a \\
{\left[C_{t}\right]_{s s} } & =\frac{-\left(a^{2} k_{2} k_{5}^{2}\right)}{k_{6}^{3}} \\
{\left[C_{2}\right]_{s s} } & =\frac{-\left(a k_{5}\right)}{2 k_{1}} \\
{\left[C_{\text {inorganic }}\right]_{s s} } & =\frac{a k_{2} k_{5}^{2}}{k_{6}^{2}\left(k_{4}+k_{3}\right)}+\frac{480 k_{4}}{k_{4}+k_{3}} .
\end{aligned}
$$

When $t$ is large the concentration of methane and carbon dioxide can be obtained from the Eqns.(3.5) and (3.6) as follows:

$$
\begin{aligned}
{\left[C H_{4}\right]=} & t\left(-a k_{5} k_{1}+\frac{a k_{3} k_{2} k_{5}^{2}}{k_{6}^{2}\left(k_{4}+k_{3}\right)}+\frac{480 k_{4} k_{3}}{\left(k_{4}+k_{3}\right)}+\right. \\
& \frac{C H_{4 i n} k_{3}}{\left(k_{4}+k_{3}\right)}+\frac{f k_{3}\left(M_{i n}-a\right)\left(k_{0}+k_{5}\right)}{\left(k_{4}+k_{3}-k_{0}-k_{5}\right)} \\
& \left.\left(\frac{1}{k_{4}+k_{3}}-\frac{1}{k_{0}+k_{5}}\right)\right)
\end{aligned}
$$

$$
\left[C O_{2}\right]=t\left[\begin{array}{l}
\frac{k_{0} a}{4 k_{1}}+a k_{5}\left(\frac{1}{2}-k_{1}\right)+\frac{3 C O_{2 i n}}{2}+480 k_{4} \\
\left(\frac{k_{4}}{\left(k_{4}+k_{3}\right)}-\frac{1}{k_{4}\left(k_{4}+k_{3}\right)^{2}}-\frac{C H_{4 i n}}{480\left(k_{4}+k_{3}\right)}-1\right) \\
-\frac{k_{1} k_{0}\left(M_{i n}-a\right)}{\left(2 k_{1}-k_{0}-k_{5}\right)}\left(\frac{1}{2 k_{1}}-\frac{1}{\left(k_{0}+k_{5}\right)}\right)+\left(C_{i n}+\frac{a k_{5}}{k_{6}}\right) \\
\left(k_{1}-\frac{k_{6}}{2}\right)+\frac{a^{2} k_{2} k_{4} k_{5}^{2}}{k_{6}^{2}\left(k_{4}+k_{3}\right)}\left(1-\frac{1}{\left(k_{4}+k_{3}\right)}\right) \\
-\left(\frac{1}{k_{6}}+\frac{1}{k_{4}+k_{3}}\right)\left(\frac{2 a k_{5} k_{4}\left(c_{i i n}+\frac{a k_{5}}{k_{6}}\right)}{k_{6}\left(k_{4}+k_{3}-k_{6}\right)}\right)+ \\
\frac{f k_{4}\left(M_{i n}-a\right)\left(k_{0}+k_{5}\right)}{\left(k_{4}+k_{3}-k_{0}-k_{5}\right)}\left(\frac{1}{\left(k_{4}+k_{3}\right)}-\frac{1}{k_{0}+k_{5}}\right)+C O_{2 i n}
\end{array}\right]
$$




\section{Numerical simulation}

The non-linear ordinary differential Equation (2.1) for the given initial conditions is being solved numerically. The function pdex4, in SCILAB which is a function of solving the initial value problems for non-linear ordinary differential equations . The numerical solution is compared with analytical results in Figs. (2) to (7) and it gives satisfactory result. The SCILAB program is also given in supplementary material of this manuscript (Appendix A).

\section{Sensitivity analysis}

Sensitivity was determined by the change in concentration caused by altering the variable or combination of variables, as measured by time parameters for $10 \mathrm{~h}$. We define the maximum change as the greatest change resulting from each combination of parameters. Similarly, the minimum change is the smallest change resulting from the combination of parameters. When a parameter was paired with itself, the change caused by altering that single parameter was used.

The sensitivity analysis yields the influence of each parameter on the concentration of volatile fatty acids, concentration of acetic acid, concentration of total inorganic carbon, concentration methane, and concentration of carbon dioxide. By evaluating the slope of concentration with respect to the desired parameters, their influence on concentration ascertained. From Table 1. Depicts the sensitivity was determined the percentage of kinetic parameters $k_{0}$ to $k_{6}$ in the concentration. It is inferred that the kinetic parameter constant $k_{5}$ has significant influence in dictating the concentration of volatile fatty acids, followed by the kinetic parameter constant $k_{0}$ and $k_{2}$.

Table 1: Sensitivity analysis of kinetic parameters using Eqns.(2.1) to (2.6)

\begin{tabular}{|c|c|c|c|c|c|c|c|c|c|c|}
\hline \multirow{2}{*}{$\begin{array}{l}\text { Concentra- } \\
\text { tion }\end{array}$} & \multicolumn{9}{|c|}{ Percentage of Kinetic Parameter } & \multirow{2}{*}{ 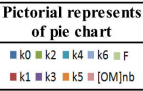 } \\
\hline & $k_{p}$ & $k_{I}$ & $k_{2}$ & $k_{3}$ & $k_{4}$ & $k_{5}$ & $k_{6}$ & {$[\mathrm{OM}]_{\mathrm{nb}}$} & $\mathrm{F}$ & \\
\hline [OM] & $49 \%$ & $0 \%$ & $0 \%$ & $0 \%$ & $0 \%$ & $49 \%$ & $0 \%$ & $1 \%$ & $0 \%$ & \\
\hline$\left[\mathrm{C}_{\mathrm{i}}\right]$ & $1 \%$ & $0 \%$ & $1 \%$ & $0 \%$ & $0 \%$ & $97 \%$ & $1 \%$ & $0 \%$ & $0 \%$ & \\
\hline$\left[\mathrm{C}_{2}\right]$ & $16 \%$ & $10 \%$ & $0 \%$ & $0 \%$ & $0 \%$ & $73 \%$ & $0 \%$ & $0 \%$ & $0 \%$ & \\
\hline$\left[\mathrm{C}_{\text {inorganici }}\right]$ & $3 \%$ & $0 \%$ & $0 \%$ & $42 \%$ & $2 \%$ & $52 \%$ & $1 \%$ & $0 \%$ & $0 \%$ & \\
\hline$\left[\mathrm{CH}_{4}\right]$ & $1 \%$ & $0 \%$ & $0 \%$ & $70 \%$ & $0 \%$ & $29 \%$ & $0 \%$ & $0 \%$ & $0 \%$ & \\
\hline$\left[\mathrm{CO}_{2}\right]$ & $0 \%$ & $0 \%$ & $0 \%$ & $15 \%$ & $0 \%$ & $79 \%$ & $1 \%$ & $0 \%$ & $5 \%$ & \\
\hline
\end{tabular}

\section{Results and discussion}

Eqns.(2.1) to (2.6) represent the new approximate analytical expression for the organic matter concentration volatile fatty acids concentration, acetic acid carbon concentration, inorganic carbon concentration, methane concentration, carbon dioxide concentration. The analytical results are compared with the numerical results in Figs.(2) to (7) for different values of parameter (numerical values of the parameters are given in Table 1). It gives good agreement with the numerical results.

Fig.2(a)-(b) represent the concentration of organic matter $[O M]$ versus time $t$. From the Fig.2(a)-(b), it is inferred that the value of organic matter concentration increases gradually when the kinetic parameter constant $k_{0}$ decreases and reaches the steady-state value when $t>5$.

Fig.3(a)-(c) show the concentration of volatile fatty acids as the function of time $t$. From the Fig.3(a)-(c), it is evident that the concentration of volatile fatty $\left[C_{i}\right]$ increases greatly and when $t=25$ it attains the steady-state value.

Fig.4(a)-(c) indicate the concentration of acetic acid $\left[C_{2}\right]$ with time $t$. From the Fig.4(a)-(c), It is confirmed that the concentration of acetic acid $\left[C_{2}\right]$ gradually increases or decreases depends upon the value of kinetic parameter constants.

The concentration of inorganic carbon $\left[\mathrm{C}_{\text {inorganic }}\right]$, methane $\left[\mathrm{CH}_{4}\right]$ and carbon dioxide $\left[\mathrm{CO}_{2}\right]$ with different values of $t$ are shown in Figs.5 to 7. The concentration profile of $\left[\mathrm{C}_{\text {inorganic }}\right],\left[\mathrm{CH}_{4}\right]$ and $\left[\mathrm{CO}_{2}\right]$ are increasing as kinetic parameter constants are increased as shown in Figs.5 to 7.

\section{Conclusion}

The time dependent non-linear ordinary differential equations have been solved analytically using the homotopy perturbation method. The mathematical model based on six segregated ordinary differential equations simulated the evolution of the 
concentration of carbon in different forms from biodegradable and non-biodegradable substrate. The transformation steps followed first or second-order kinetics. The kinetic constants corresponding to these stages were found $k_{0}$ to $k_{6}$ decrease markedly with the load added to the reactor, showing the occurrence of an inhibition process. The kinetic model proposed was able to predict the evolution of the different carbon involved in the anaerobic digestion of waste water showing the occurrence of an inhibition phenomenon when the substrate ratio $k_{5}$ decreased. In this paper mathematical expression of organic matter concentration $[O M]$, volatile fatty acid concentration $\left[C_{i}\right]$, acetic acid concentration $\left.C_{2}\right]$, total inorganic concentration $\left[C_{\text {inorganic }}\right]$, methane concentration $\left[\mathrm{CH}_{4}\right]$, carbon dioxide $\left[\mathrm{CO}_{2}\right]$ concentration is reported. An excellent agreement with existing steady-state results is noted. Furthermore, the numerical simulation was in excellent agreement with analytically obtained concentration. The analytical results will be useful for the design and optimization of industrial bio fuel production.

\section{Appendix A}

Matlab/Scilab program to find the numerical solution of Eqns.(2.1) to (2.6).

function main 123456

options= odeset('RelTol','1e-6','Stats','on');

$\mathrm{X} 0=[1000 ; 0 ; 0 ; 400 ; 0 ; 0]$;

tspan $=[0 ; 40]$;

tic

[t,X]=ode45(@TestFunction,tspan,X0,options);

toc

figure

hold on

$\% \operatorname{plot}(\mathrm{t}, \mathrm{X}(:, 1))$

$\% \operatorname{plot}(\mathrm{t}, \mathrm{X}(:, 2))$

$\%$ plot $(\mathrm{t}, \mathrm{X}(:, 3))$

$\% \operatorname{plot}(\mathrm{t}, \mathrm{X}(:, 4))$

$\% \operatorname{plot}(\mathrm{t}, \mathrm{X}(:, 5))$

$\operatorname{plot}(\mathrm{t}, \mathrm{X}(:, 6))$

legend('x1','x2','x3','x4','x5','x6')

ylabel('x')

xlabel('t')

return

Function[dx_dt] $=$ TestFunction $(\mathrm{t}, \mathrm{x})$

$\mathrm{k} 1=.5$;

$\mathrm{k} 0=.5$;

$\mathrm{k} 5=.002$;

$\mathrm{k} 2=0.00001$;

$\mathrm{c}=130$;

$\mathrm{f}=1$;

$\mathrm{k} 6=.2$;

$\mathrm{k} 3=.01$;

$\mathrm{k} 4=.001$;

$\mathrm{dx}_{-} \mathrm{dt}(1)=-(\mathrm{k} 0+\mathrm{k} 5)^{*}(\mathrm{x}(1)-\mathrm{c})$;

$\mathrm{dx}_{\mathrm{d}} \mathrm{dt}(2)=\mathrm{k} 5 *(\mathrm{x}(1)-\mathrm{c})-\mathrm{k} 6 * \mathrm{x}(2)-\mathrm{k} 2 * \mathrm{x}(2) \wedge 2$;

$\mathrm{dx}_{\mathrm{d}} \mathrm{dt}(3)=\mathrm{k} 0 *(\mathrm{x}(1)-\mathrm{c})+\mathrm{k} 6 * \mathrm{x}(2)-2 * \mathrm{k} 1 * \mathrm{x}(3)$;

$\mathrm{dx} \_\mathrm{dt}(4)=\mathrm{k} 4 * 480-\mathrm{k} 4 * \mathrm{x}(4)+\mathrm{k} 2 * \mathrm{x}(2) \wedge 2-\mathrm{k} 3 * \mathrm{x}(4)$

$-\mathrm{f} *(\mathrm{k} 0+\mathrm{k} 5) * \mathrm{x}(1)+\mathrm{f} *(\mathrm{k} 0+\mathrm{k} 5) * \mathrm{c}$;

$\mathrm{dx}_{-} \mathrm{dt}(5)=\mathrm{k} 1 * \mathrm{x}(3)+\mathrm{k} 3 * \mathrm{x}(4)$;

$\mathrm{dx} \_\mathrm{dt}(6)=\mathrm{k} 1 * \mathrm{x}(3)-\mathrm{k} 4 *(480-\mathrm{x}(4))$;

$\mathrm{dx} \_\mathrm{dt}=\mathrm{dx} \_\mathrm{dt}$ ';

return 


\section{Appendix B}

\section{Nomenclature and Units}

\begin{tabular}{|c|c|c|}
\hline Symbols & Definitions & Units \\
\hline$[O M]$ & Organic matter concentration & $\mathrm{mg} \mathrm{C} / \mathrm{L}$ \\
\hline$[O M]_{b}$ & Organic matter bio-degradable & $\mathrm{mg} \mathrm{C} / \mathrm{L}$ \\
\hline$[O M]_{n b}$ & $\begin{array}{l}\text { Organic matter non-bio degrad- } \\
\text { able }\end{array}$ & $\mathrm{mg} \mathrm{C} / \mathrm{L}$ \\
\hline$\left[C_{i}\right]$ & $\begin{array}{l}\text { Concentration of carbon as } \\
\text { volatile fatty acids having carbon }\end{array}$ & $\mathrm{mg} \mathrm{C} / \mathrm{L}$ \\
\hline$\left[C_{2}\right]$ & $\begin{array}{l}\text { Concentration of acetic acid car- } \\
\text { bon }\end{array}$ & $\mathrm{mg} \mathrm{C} / \mathrm{L}$ \\
\hline$\left[C_{i n}\right]$ & $\begin{array}{l}\text { Total concentration of inorganic } \\
\text { carbon } \mathrm{HCO}_{3}, \mathrm{CO}_{2}^{3} \text { and } \mathrm{CO}_{2}\end{array}$ & $\mathrm{mg} \mathrm{C} / \mathrm{L}$ \\
\hline$\left[\mathrm{CH}_{4}\right]$ & $\begin{array}{l}\text { Concentration of methane in the } \\
\text { biogas }\end{array}$ & $\mathrm{mg} \mathrm{C} / \mathrm{L}$ \\
\hline$\left[\mathrm{CO}_{2}\right]$ & $\begin{array}{l}\text { Concentration of carbon dioxide } \\
\text { in the biogas }\end{array}$ & $\mathrm{mg} \mathrm{C} / \mathrm{L}$ \\
\hline$\left[k_{0}\right]$ & $\begin{array}{l}\text { Kinetic constant for Organic } \\
\text { matter transformed into the } \\
\text { Acetic acid }\end{array}$ & $h^{-1}$ \\
\hline$\left[k_{1}\right]$ & $\begin{array}{l}\text { Kinetic constant for acetic acid } \\
\text { transformed into the methane } \\
\text { and carbon dioxide }\end{array}$ & $h^{-1}$ \\
\hline$\left[k_{2}\right]$ & $\begin{array}{l}\text { Kinetic constant for degradation } \\
\text { of carbon acids }\end{array}$ & $h^{-1}$ \\
\hline$\left[k_{3}\right]$ & $\begin{array}{l}\text { Kinetic constant for methane } \\
\text { from soluble inorganic carbon }\end{array}$ & $h^{-1}$ \\
\hline$\left[k_{4}\right]$ & $\begin{array}{l}\text { Equilibrium constant for carbon } \\
\text { dioxide }\end{array}$ & $h^{-1}$ \\
\hline$\left[k_{5}\right]$ & $\begin{array}{l}\text { Kinetic constant for organic mat- } \\
\text { ter transformed into the Carbon } \\
\text { acids }\end{array}$ & $h^{-1}$ \\
\hline$\left[k_{6}\right]$ & $\begin{array}{l}\text { Kinetic constant for transformed } \\
\text { of carbon into acetic acids }\end{array}$ & $h^{-1}$ \\
\hline$F$ & Operator & $(g / L)$ \\
\hline$T$ & Time & $T$ \\
\hline
\end{tabular}

\section{Appendix C}

\section{Solution Eqns.(2.1) to (2.6) using Homotopy perturbation method}

To illustrate the basic idea of this method, we consider the following non linear differential equation: $L(u)+N(u)-f(r)=0$ where $L$ and $N$ are the linear and non linear part of a differential equation. 
We construct a homotopy for the non linear differential equation Eqns.(2.1) to (2.6) as follows:

$$
\begin{aligned}
& (1-p)\left(\frac{d[O M]}{d t}+\left(k_{0}+k_{5}\right)[O M]-\left(k_{0}+k_{5}\right)[O M]_{n b}\right)+p\left(\frac{d[O M]}{d t}+\left(k_{0}+k_{5}\right)[O M]-\left(k_{0}+k_{5}[O M]_{n b}\right)=0\right. \\
& (1-p)\left(\frac{d\left[C_{i}\right]}{d t}+k_{6}\left[C_{i}\right]-k_{5}[O M]_{n b}\right)+p\left(\frac{d\left[C_{i}\right]}{d t}+k_{6}\left[C_{i}\right]+k_{5}[O M]_{n b}-k_{0}[O M]+k_{2}\left[C_{i}\right]^{2}\right)=0 \\
& (1-p)\left(\frac{d\left[C_{2}\right]}{d t}+2 k_{1}\left[C_{2}\right]+k_{0}[O M]_{n b}\right)+p\left(\frac{d\left[C_{2}\right]}{d t}+2 k_{1}\left[C_{2}\right]-k_{6}\left[C_{i}\right]-k_{0}[O M]_{n b}-k_{0}[O M]\right)=0 \\
& (1-p)\left(\frac{d\left[C_{\text {inorganic }}\right]}{d t}+\left(k_{4}+k_{3}\right)\left[C_{\text {inorganic }}\right]-480 k_{4}\right)+ \\
& \left.p\left(\frac{d\left[C_{\text {inorganic }}\right]+\left(k_{4}+k_{3}\right)}{d t}+\left[C_{\text {inorganic }}\right]-480 k_{4}-k_{2}\right)\left[C_{i 0}\right]^{2}-f\left(k_{5}+k_{0}\right)\left[O M_{O}-O M_{n b}\right]\right)=0 \\
& (1-p)\left(\frac{d\left[\mathrm{CH}_{4}\right]}{d t}-k_{1}\left[C_{2}\right]-k_{3}\left[C_{i n}\right]\right)+p\left(\frac{d\left[\mathrm{CH}_{4}\right]}{d t}-k_{1}\left[C_{2}\right]+k_{3}\left[C_{i n}\right]\right)=0 \\
& (1-p)\left(\frac{d\left[C O_{2}\right]}{d t}-k_{1}\left[C_{2}\right]-k_{4}\left[C_{i n}\right]+k_{4} 480\right)+p\left(\frac{d\left[\mathrm{CO}_{2}\right]}{d t}-k_{1}\left[C_{2}\right]-k_{4}\left[C_{i n}\right]+k_{4} 480\right)=0
\end{aligned}
$$

Supposing the approximate solution of Eqns. (A1) to (A6) have the form

$$
\begin{cases}{[\mathrm{OM}]} & =O M_{0}+p O M_{1}+. . \\ {\left[C_{i}\right]} & =C_{i 0}+p C_{i 1}+. . \\ {\left[C_{2}\right]} & =C_{20}+p C_{21}+. . \\ {\left[C_{i n}\right]} & =C_{i n 0}+p C_{i n 1}+. . \\ {\left[\mathrm{CO}_{2}\right]} & =\mathrm{CO}_{20}+p C O_{21}+. . \\ {\left[\mathrm{CH}_{4}\right]} & =\mathrm{CH}_{40}+p C \mathrm{CH}_{41}+. .\end{cases}
$$

Substituting Eqns. (A1) to (A6) in Eqn. (A7) and comparing the coefficients of like powers of $p$, the following equations are obtained.

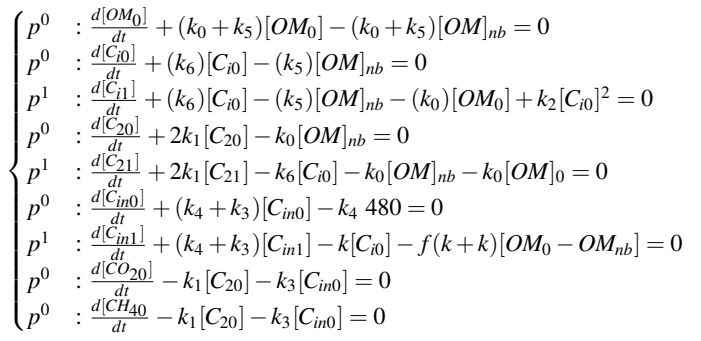

The initial conditions are at

$$
\begin{array}{r}
t=0,\left[\mathrm{OM}_{0}\right]=M_{\text {in }},\left[C_{i 0}\right]=C_{\text {iin }}, \\
{\left[C_{20}\right]=C_{2 i n},\left[C_{\text {inorganic }}\right]=C_{\text {inin }},} \\
{\left[\mathrm{CH}_{40}\right]=\mathrm{CH}_{4 i n},\left[\mathrm{CO}_{20}\right]=\mathrm{CO}_{2 \text { in }}}
\end{array}
$$

and

$$
\begin{aligned}
{\left[O M_{i}\right] } & =0,\left[C_{i i}\right]=0,\left[C_{2 i}\right]=0,\left[C_{i}\right]=0, \\
{\left[C_{4 i}\right] } & =0,\left[C_{2 i}=0, \text { for } i=1,2,3 \ldots\right.
\end{aligned}
$$

Solving the Eqn. (A8) and using the initial conditions Eqns. (A9) and (A10) we get approximate solution of Eqns.(3.1) to (3.6) in the text. 

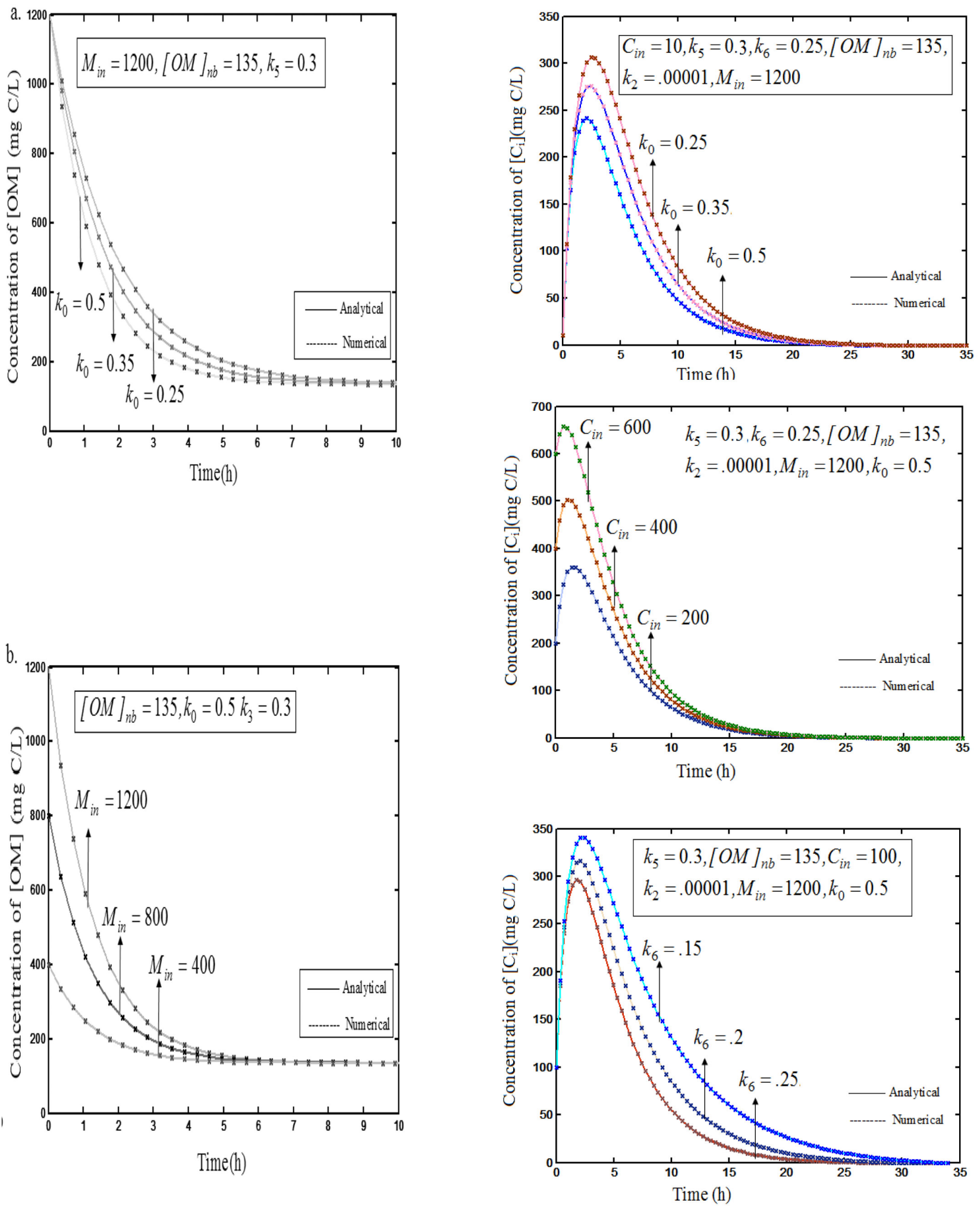

Fig.2(a)-(b): Concentration profiles of organic matter [OM] versus time $t$ for various values of is plotted using Eqn.(2.1).

Fig.3(a)-(c): Concentration profiles of volatile fatty acids $\left[C_{i}\right]$ versus time $t$ for various values of $k_{0}, k_{5}, C_{i i n}$ is plotted using Eqn.(2.2). 

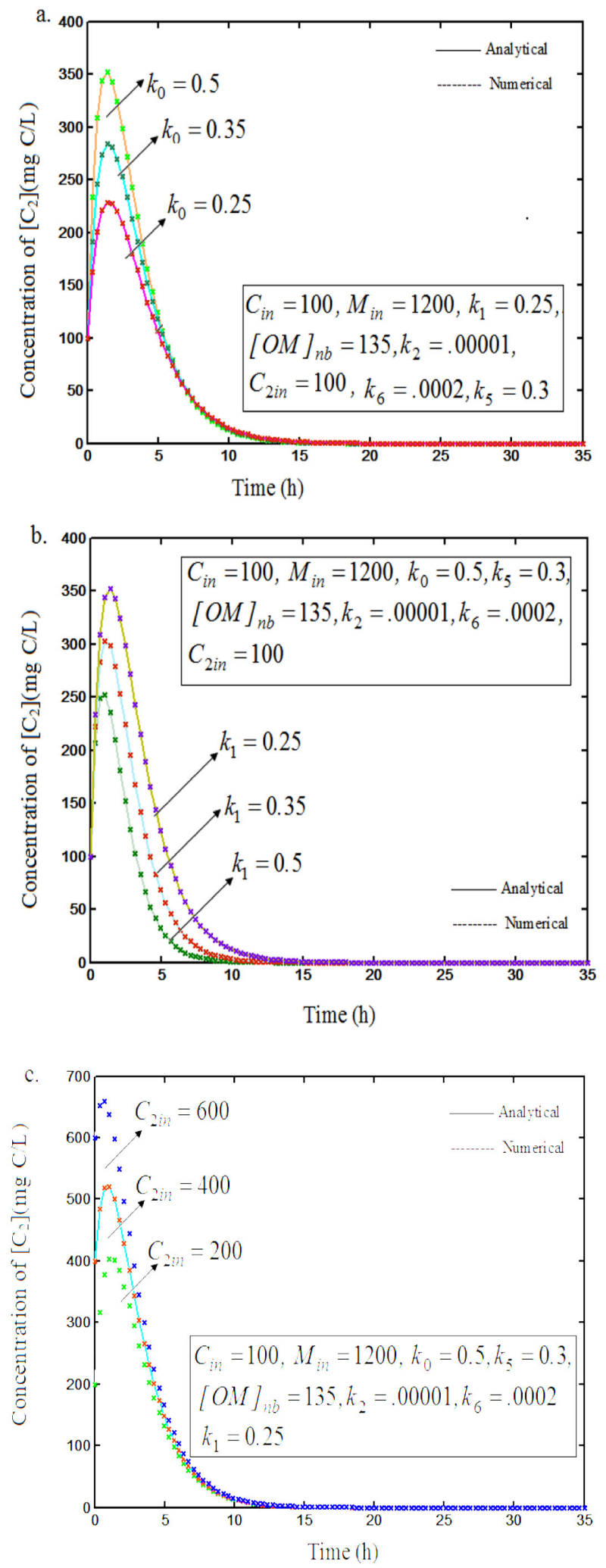

Fig.4(a)-(c): Concentration profiles of acetic acids $\left[C_{i}\right]$ versus time $t$ for various values of $k_{0}, k_{1}, C_{2 i n}$ is plotted using Eqn.(2.3).
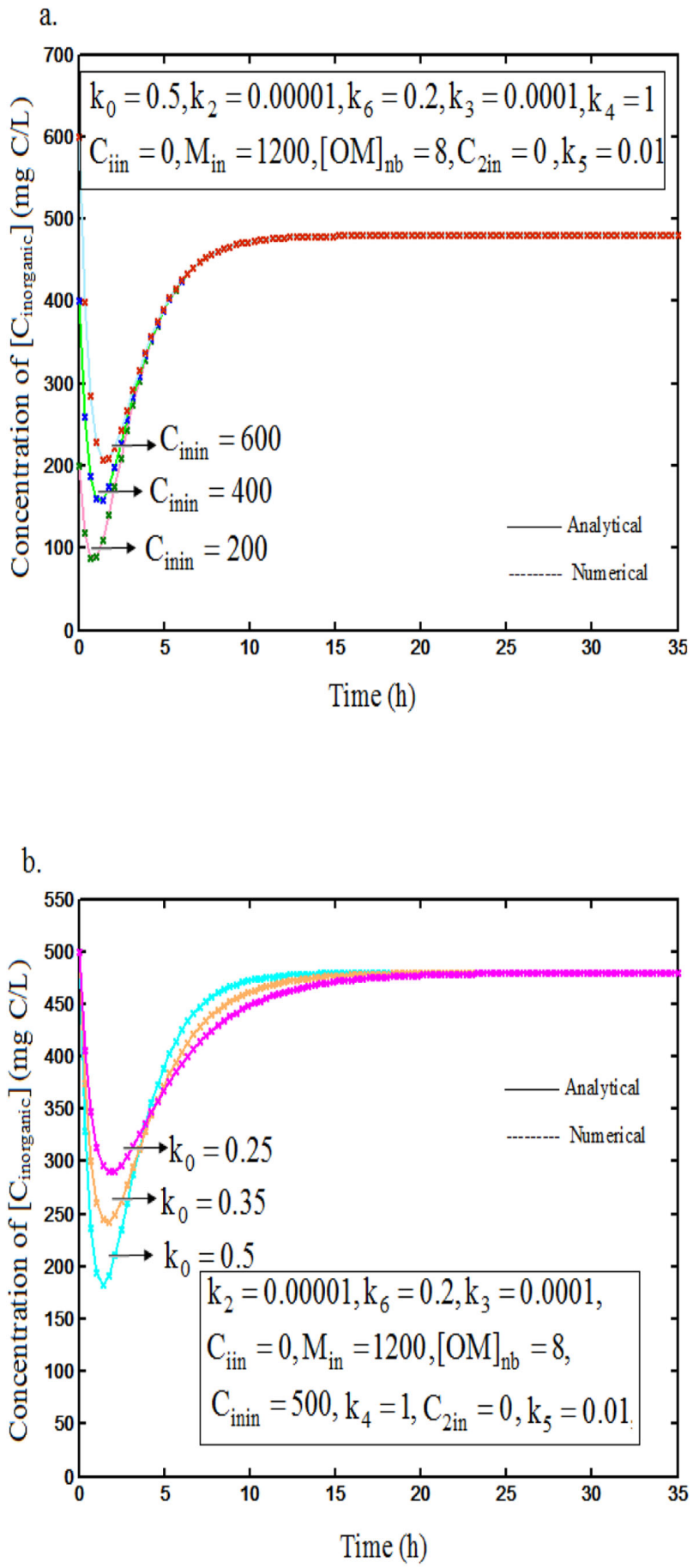

Fig.5(a)-(b): Concentration profiles of total inorganic carbon $\left[C_{\text {inorganic }}\right]$ versus time $t$ for various values of $k_{0}, C_{\text {inin }}$ is plotted using Eqn.(2.4). 


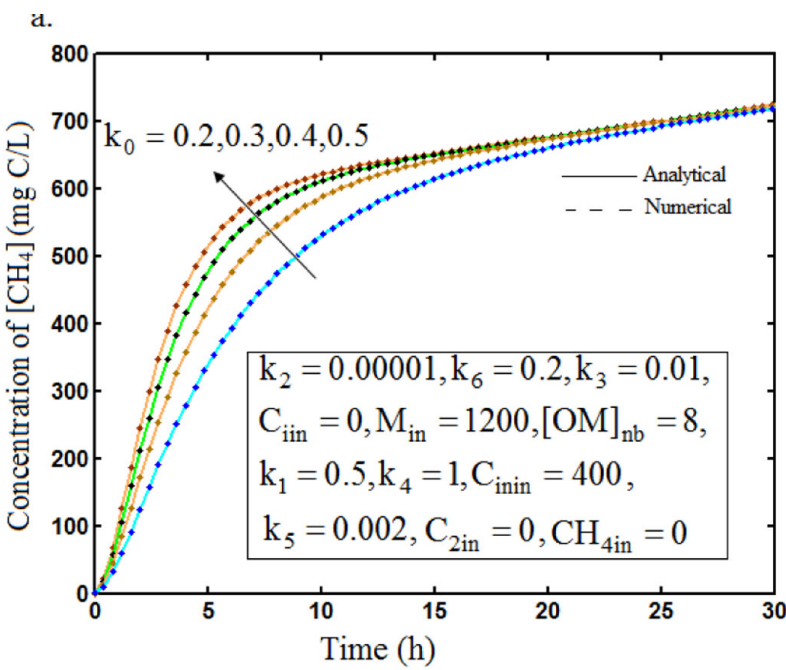

b.
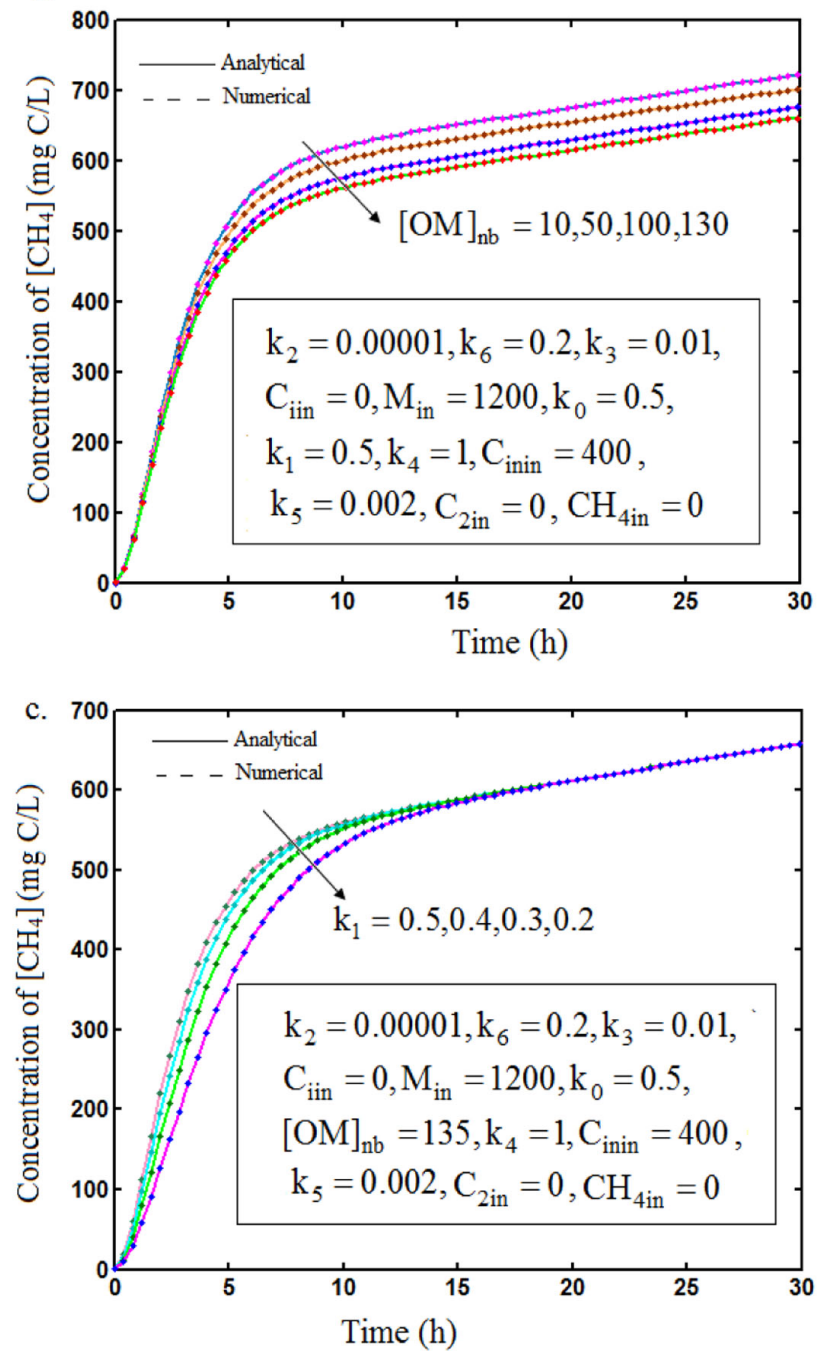

Fig.6(a)-(c): Concentration profiles of methane $\left[\mathrm{CH}_{4}\right]$ versus time $t$ for various values of $k_{0}, k_{1},[O M]_{n b}$ is plotted using Eqn.(2.5)

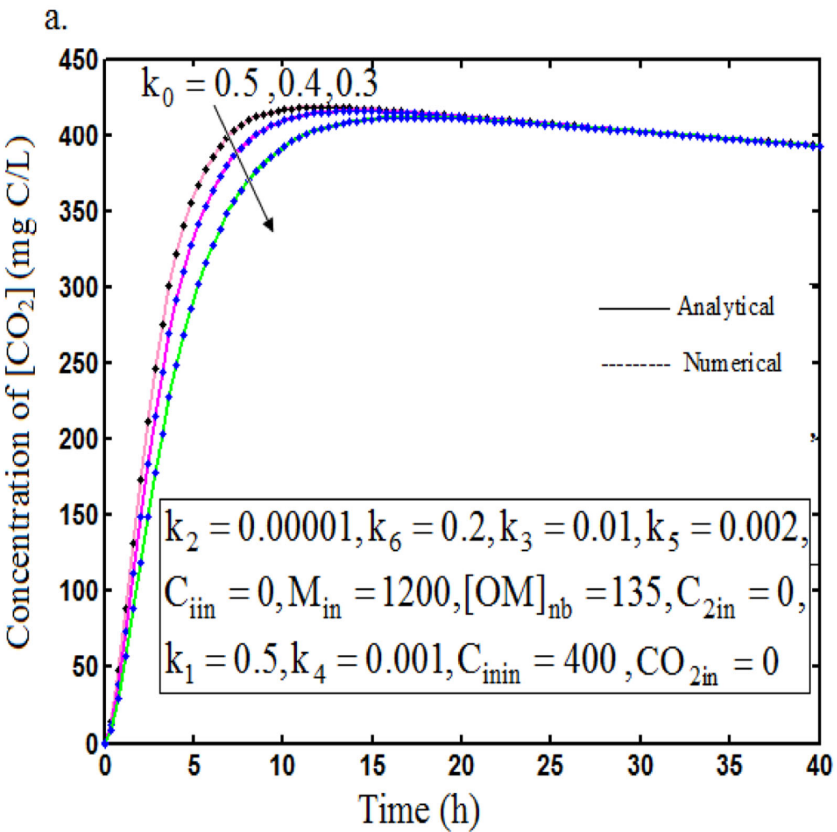

b.

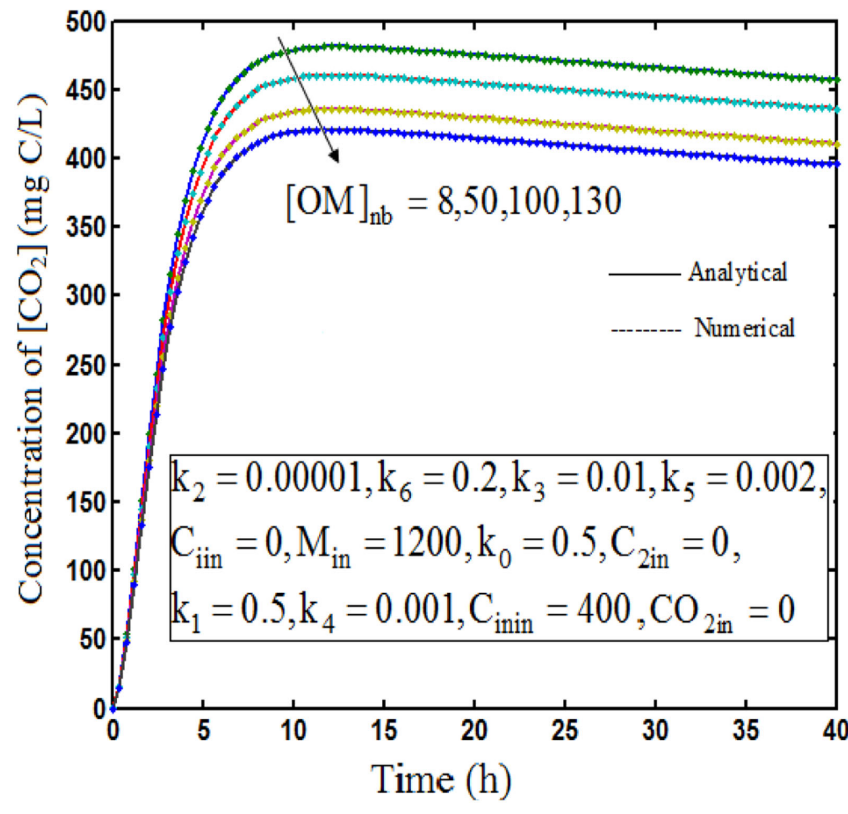

Fig.7(a)-(b): Concentration profiles of carbon dioxide $\left[\mathrm{CO}_{2}\right]$ versus time $\mathrm{t}$ for various values of $k_{0},[O M]_{n b}$ is plotted using Eqn.(2.6). 


\section{References}

[1] M.S. Rao, S.P. Singh, Bioenergy conversion studies of organic fraction of MSW: Kinetic studies and gas yieldorganic loading relationships for process optimisation, Bio resource Technology, 95 (2004), 173-185.

[2] V. Dhanalakshmi Sridevi and R.A. Ramanujam Biogas Generation in a Vegetable Waste Anaerobic Digester: An Analytical Approach, Research Journal of Recent Sciences, 1(3) (2012), 41-47.

[3] Eman Zakaria Gomaa, Bioconversion of orange peels for ethanol production using Bacillus subtilis and Pseudomonas aeruginosa, African Journal of Microbiology Research, 7(14) (2013), 1266-1277.

[4] M.A. Martín, J.A. Siles, H. El Bari, A.F. Chica, A. Martín, Orange peel: organic waste or energetic resource?, Technologies/systems for different manure and organic waste treatment options, 2010.

[5] Mario Novak, Predrag Horvat, Mathematical modelling and optimisation of a waste model, water treatment plant by combined oxygen electrode and biological waste water treatment, Applied Mathematical Modelling, 36 (2012), 3813-3825.

[6] J.H. He, Homotopy perturbation technique computation methods, Applied Mechanics Engineering, 178 (1999), 257-262.

[7] D.H. Shou, Homotopy perturbation method for nonlinear oscillators, Computers and Mathematics with Applications, 58(11-12) (2009), 2456-2459.

[8] J.H. He, Homotopy perturbation method a new nonlinear analytical technique, Applied mathematics and Computation, 135 (2003), 73-79.

[9] J.H. He, The homotopy perturbation method for nonlinear oscillators with discontinuities,Applied mathematics and Computation, 151(2004), 287-292.

[10] J.H. He, Application of homotopy perturbation method to nonlinear wave equations. Chaos, Solitons \& Fractals, 26 (2005), 695-700.

[11] J.H. He, Some asymptotic method for strongly nonlinear equation. International Journal Modern Physics, 20(10) (2006), 1141-1199.

[12] María de los Ángeles Martín Santos, José Ángel Siles López, Arturo Francisco Chica Pérez, Antonio Martín Martín, Modelling the anaerobic digestion of wastewater derived from the pressing of orange peel produced in orange juice manufacturing, Bioresource Technology, 101 (2010), 3909-3920. 